\title{
La resurrección del autor en la crítica francesa actual (2008-2011). \\ El caso de la crítica de reatribución de Pierre Bayard ${ }^{*}$
}

Recibido: agosto 8 de 2017 | Aceptado: 9 de julio de 2018

DOI: 10.17230/co-herencia.15.29.10

Nicolás Garayalde*

negarayalde@gmail.com

Resumen Este artículo ofrece un análisis del concepto de autor que se desprende de los ensayos del crítico francés Pierre Bayard, en el contexto de las diversas resurrecciones del autor que han ocurrido desde la sentencia de muerte dictada por Roland Barthes en 1968. Para ello, tendremos en cuenta dos problemas relacionados con la noción de autor en la teoría literaria entre lo que Bayard llama hermenéutica y relativismo: 1) la trascendentalización de la experiencia literaria, y 2) la anarquía interpretativa. A su vez, estos dos problemas nos conducirán a indagar cuál es el lugar que ocupa el autor en el marco de referencia del texto y cómo condiciona la experiencia de lectura.

Palabras clave:

Autor, Bayard, hermenéutica, relativismo, marco de referencia.

\section{The resurrection of the author in current} French literary criticism (2008-2011).

The case of Pierre Bayard's re-attribution criticism

\begin{abstract}
This paper aims to analyse the concept of author which can be derived from the essays of the French literary critic Pierre Bayard, in the context of the various resurrections of the author that have occurred since Roland Barthes's authorial death sentence in 1968. To this end, two problems will be considered which have been present in the reflection of literary theory on the author issue, midway between what Bayard named hermeneutics and relativism: the transcendentalization of the literary experience and the interpretative anarchy. In turn, these two problems will lead to query the place occupied by the author within the reference framework of the text and how it conditions the reading experience.
\end{abstract}

\section{Keywords:}

Author, Bayard, hermeneutics, relativism, reference framework.
El presente artículo surge como parte de una investigación sobre teorías de la lectura en la crítica francesa contemporánea financiada por una beca doctoral (2012-2017) y una beca postdoctoral (20172019) de CONICET (Argentina).

** Facultad de Filosofía y Humanidades, Universidad Nacional de Córdoba, Argentina. ORCID: 0000-0002. 0692- 4330 
La mentada muerte del autor, que ocurrió a lo largo del siglo Xx y tomó su carácter más radical en la declaración de Roland Barthes en 1968, decantó en una resurrección teóricamente diversa, signada por lecturas heterogéneas tanto de los textos del crítico francés como de la célebre conferencia "Qu'est-ce qu'un auteur?" de Michel Foucault.

$\mathrm{Si}$ recorremos los modos en que esta resurrección se produjo, ${ }^{1}$ podemos advertir dos problemas fundamentales que la atraviesan.

Por un lado, todo intento de resurrección ha estado marcado por una cautela -con frecuencia insuficiente- para no producir una conceptualización del autor de carácter trascendental, asociada tradicionalmente tanto al positivismo biográfico de tipo lansoniano - contra lo cual reaccionan el formalismo y la Nueva Crítica- como a la perspectiva fenomenológica de la Escuela de Ginebra -contra la cual reaccionan el posestructuralismo y la versión deconstruccionista norteamericana. El propio Barthes es acusado de no poder abandonar el carácter trascendental vinculado a la conciencia autoral fenomenológica allí donde al decretar la muerte del autor erige la écriture en su lugar. Foucault recibe una acusación semejante por parte de John Burke (1989) por su concepto de "fundadores de discursividad". Este problema podría ser formulado de la siguiente manera: cuando un crítico construye una conceptualización del autor, ien qué medida está involucrando un foco trascendental, una sustancia que delimita y controla el texto como centro?

Por otro lado, muchos de los críticos que pugnaron por un retorno del autor parecen preocupados por las derivas de la lectura promovidas por la utopía textualista de Barthes, por la supuesta libertad interpretativa desplegada a partir de los años 60 con el extenso abanico de las teorías de la recepción y por la desregulación interpretativa consecuente: ¿cómo evaluar el valor de la crítica y de la literatura una vez abandonado el criterio de autor como fuente de legitimación?; ¿cuáles son los límites de la interpretación una vez apartado el elemento centralizador hacia el cual apuntaba la

1 Para un exhaustivo estudio de las diversas resurrecciones del autor que se produjeron tras la sentencia de Barthes hasta 2005, cfr. Topuzian (2014) Muerte y resurrección del autor (1963-2005). Tomamos la retórica de la resurrección tanto de este trabajo de Topuzian como de la tesis doctoral que John Burke dedicó en 1989 a la noción de autor en Barthes, Foucault y Derrida: The Death and Return of the Author. 
lectura? El temor ante la amenaza de la anarquía interpretativa, siempre presente ante cada estocada contra cualquier centro de control de la obra, es particularmente notable cuando el autor se encuentra bajo ataque.

Ambos problemas -la amenaza de una concepción trascendental del acontecimiento literario y laamenaza de la anarquía interpretativaorbitan en torno a dos formas de concebir el texto que, siguiendo a Pierre Bayard (2002), podemos nombrar hermenéutica y relativismo.

La primera, de raigambre romántica, apunta hacia la unidad orgánica y está interesada en saber cómo el autor se inscribe en el texto y lo estabiliza. Para Bayard, esta hermenéutica está ligada directamente al poder de determinación del sentido que opera el autor como figura central que otorga "la unidad del texto literario, o, si se quiere, la confusión entre texto general y textos singulares" (2002, p. 80). ${ }^{2}$

La forma relativista, en cambio, se apoya en el carácter paradojal del texto al preocuparse por saber cómo el lector se inscribe en él y lo desestabiliza. Rechaza entonces la idea de unificación, oponiéndose incluso a la posibilidad de acceso a un texto general que estaría constantemente subvertido por la multiplicidad de textos singulares que se producen en cada acto de lectura.

Una y otra representan las puntas en las que una de las dos amenazas toma mayor potencia. Ninguna de las dos supone una adhesión a la muerte del autor. En todo caso, si la segunda acepta la tesis desarrollada por Barthes lo hace en la medida en que, como sucede en el proceso que va de "La mort de l'auteur" (1968) a Sade, Fourier, Loyola (1971), se presupone como antesala de una reformulación del autor.

En general, será difícil encontrar críticos que explícitamente se asuman cercanos a la primera de estas concepciones del texto y su consecuente manera de entender el autor. Lo que podemos advertir es que en ciertos casos se desarrolla una posición que, al buscar conjurar la deriva interpretativa aguijoneada por el textualismo barthesiano, recae sobre una figura de autor (o en uno de sus avatares) como centro, basada en formas de intencionalismo moderado o fuerte

2 Todas las traducciones de los textos en francés y en inglés son de mi autoría. 
(Lecercle, 2008) que asumen un querer-decir y una intención de origen, a pesar de los recaudos tomados. Un ejemplo notable de este último caso parece estar representado por la propuesta que despliega Maurice Couturier en La figure de l'auteur (1995), que oscila entre una construcción por parte del lector y una proyección de la intención del autor.

Tampoco será fácil encontrar autores que asuman una perspectiva relativista sin matices, lo que es particularmente notable en el caso de las teorías orientadas al lector que surgieron como reacción a la moda inmanentista desarrollada por el New Criticism y el estructuralismo a uno y otro lado del Atlántico. Aun en los teóricos en los que es posible encontrar posiciones caracterizadas por un subjetivismo osado que sitúa completamente en cada lector particular la construcción del texto, no tardamos en hallar reparos que matizan tal relativismo. Un ejemplo notable, como veremos más adelante, es el de Norman Holland: por un lado, postula la identidad del lector como origen de la construcción de sentido de un texto -al que define como "manchas de carbón negro en pulpa de madera seca" (1973, p. 2)-; por otro, no tarda en matizar tal subjetivismo radicalmente situado en el lector valorando la interacción entre la identidad del lector y la del autor en la elaboración del sentido, así como considerando nociones como códigos y cánones que atraviesan a todos los lectores de una cultura determinada y regulan sus lecturas.

En otros casos, encontramos teóricos que parecen comprometer aspectos tanto relativistas como hermenéuticos, asumiendo posiciones de compromiso que pretenden evadir el trascendentalismo de un lado y la anarquía interpretativa del otro. Paradigmáticos en este sentido son los autores pertenecientes a la llamada estética de la recepción alemana, en la estela de la tradición fenomenológico-hermenéutica. Así, Hans Robert Jauss afirmaba taxativamente que la historia de la literatura había sido "durante demasiado tiempo la historia de los autores y de las obras" (1987, p. 59); era tiempo, pues, de considerar al lector. Pero la inscripción de este lector de ninguna manera se podía concebir en los términos de una desestabilización del texto; mucho menos podía afectar la aspiración de una concepción armónica de la obra de arte, configurada en el marco de la comprensión dialógica entre el horizonte de expectativas y el de recepción. E incluso la 
focalización sobre el lector -"tercer componente", al decir de Jauss, silenciado o reprimido- parece desarrollarse con una mirada bizca: frente al lector, el ojo se desvía al texto. Tal es la operación de Wolfgang Iser -otro de los renombrados integrantes de la Universidad de Constanza-, quien interesándose en la lectura desarrolla una teoría del efecto "anclada en el texto" que se muestra muy preocupada -en sintonía con la fenomenología en la cual se inscribe- por mantener una posición que no reduzca la obra de arte ni al texto ni al lector, concibiéndola en cambio como resultado de un proceso dialéctico entre el polo artístico (que describe el texto creado por el autor) y el polo estético (que describe la concreción realizada por el lector): "la obra -dice Iser- no se halla totalmente libre de aptitudes que le introduce el lector, aun cuando tales aptitudes sean activadas según los condicionamientos del texto. Allí, pues, donde el texto y el lector convergen, ése es el lugar de la obra literaria" (1987, p. 44). Pero esta convergencia -en la que, de acuerdo con la concepción de un Georges Poulet al que Iser adhiere, el lector presta su conciencia a la conciencia autoral- se desarrolla en el marco de las posibilidades ya configuradas por la estructura del texto: "se le propone al lector una determinada estructura del texto, que le obliga a tomar un punto de mira, que a su vez permite producir la integración solicitada de las perspectivas del texto" (Iser, 1987, p. 65). Preocupado por evitar una teoría de la lectura contaminada por la psicología, Iser construye un modelo dialéctico en el que el lector se reduce a estrategias textuales y el trascendentalismo autoral parece ocupado por una dialéctica textual en el que dialogan la conciencia del autor y la del lector. El lector, más que inscribirse en el texto, se reduce a elegir una de las posibilidades ya escritas en él. ${ }^{3}$

Ciertamente, la muerte del autor supuso un condicionamiento generalizado sobre su resurrección y hay un personaje del que será difícil volver a escuchar: el autor real o empírico. En todo caso, los autores que vuelven del más allá lo hacen bajo formas que oscilan de diversas maneras entre la construcción textual y la del lector, y cuando en algunos críticos la persona del autor mantiene su

3 He desarrollado más extensamente esta argumentación en Las conveniencias de la no-lectura. Hacia una pedagogía de la interpretación creativa (Garayalde, 2014). Véase específicamente el capítulo "Estética de la recepción". 
presencia lo hace mediante un disfraz de compromiso que procura colar la presencia del querer-decir.

Una de las cuestiones que sirve de brújula para entender la manera en que cada formulación del autor se construye en el abanico que va de la hermenéutica al relativismo consiste en atender la topografía de la obra y los límites que la configuran. En otras palabras, al analizar un crítico y preguntarnos qué entiende por autor, una buena manera es preguntarse cuál es la posición que ocupa esa figura en el universo cartográfico de la obra: ¿forma parte de ella o se ubica en una posición de exterioridad?; ¡la precede o es su efecto?; ¡condiciona la interpretación o es su resultado?

En el presente artículo quisiéramos analizar, a la luz de estas cuestiones señaladas, una de las propuestas de resurrección más recientes en la crítica literaria francesa. Nos referimos al ensayista Pierre Bayard, específicamente a la noción de autor que se desprende de aquello que él mismo llama "crítica de reatribución". Para ello, nos enfocaremos en el ensayo Et si les oeuvres changeaient d'auteur? (2010), aunque será necesario acudir a otros de sus ensayos en los que se desarrolla una noción de autor en el marco de una teoría de la lectura.

\section{La crítica de reatribución}

La conceptualización del autor en Bayard se establece por la vía de lo que denomina crítica de reatribución, establecida a partir de la sugerencia que Borges desliza al final del cuento "Pierre Ménard, autor del Quijote":

Ménard (acaso sin quererlo) ha enriquecido mediante una técnica nueva el arte detenido y rudimentario de la lectura: la técnica del anacronismo deliberado y de las atribuciones erróneas. Esa técnica de aplicación infinita nos insta a recorrer la Odisea como si fuera posterior a la Eneida y el libro Le jardin du Centaure de madame Henri Bachelier como si fuera de madame Henri Bachelier. Esa técnica puebla de aventura los libros más calmosos. Atribuir a Louis Ferdinand Céline o a James Joyce la Imitación de Cristo ¿no es una suficiente renovación de esos tenues avisos espirituales? (1996, p. 55, el énfasis es mío)

Observamos aquí una de las estrategias habituales en Bayard, en el marco de un cuestionamiento de las fronteras entre la literatura, la crítica y la teoría: la teoría ficcional. Bayard recurre a la literatura como 
fuente de saber teórico y construye teoría produciendo literatura: la técnica del anacronismo deliberado dará lugar a Le plagiat par anticipation (2009) -donde se sostiene la tesis según la cual autores del pasado han plagiado a otros del futuro-; la atribución errónea será el método empleado en Et si les oeuvres changeaient d'auteur? (2010). En éste último, procurará leer obras de la literatura universal como si hubiesen sido escritas por otros autores: L'étranger, por Kafka; Hamlet, por Edward de Vere. La teoría ficcional, género híbrido que habita las fronteras entre la literatura y la teoría, permite a Bayard desplegar lo que podemos llamar, recuperando una expresión de Thomas Kuhn (1971), experimentos imaginarios: ejercicios literarios que imaginan una situación natural, sin llevarla a cabo en la realidad, con la expectativa de que ofrezca algún conocimiento válido.

Como lo sugiero en otro trabajo (Garayalde, 2018), las operaciones críticas de Bayard (y la teoría de la lectura que de ellas se desprende) se construyen en un quiasmo teórico entre la deconstrucción y el psicoanálisis. Por un lado, el concepto de autor se articula a partir de una operación irónica en la cual la subversión proviene de la afirmación de lo subvertido. El objetivo de esta estrategia radica en una reformulación del autor a través de un socavamiento de las dicotomías autor/lector y exterior/interior. En Et si les oeuvres changeaient d'auteur ?, la categoría de autor es la llave de acceso de interpretación de la obra. Es decir, la interpretación depende del autor; es a través de él que el corpus de obras que trabaja Bayard es leído. Pero en el mismo gesto se produce un trabajo de problematización conceptual al desarrollar un procedimiento de reatribución: "hecho de atribuir una obra a un autor diferente al que generalmente se ha atribuido" (2010, p. 156). Bayard parece leer las obras literarias desde una concepción hermenéutica, interesándose en cómo el autor se inscribe en el texto. Pero en el movimiento en que el autor es puesto en el centro de la escena, la misma categoría es descentrada y deconstruida, cuestionándola como herramienta hermenéutica. El autor se constituye como un centro determinante de la interpretación, pero al precio de volverse él mismo el producto de una construcción interpretativa. Por otro lado, ésta última es llevada a cabo por un lector entendido como sujeto del inconsciente: el autor es una construcción ficcional, novelada, del inconsciente del lector. 
Como veremos, esto tiene notables implicancias para los problemas planteados anteriormente: la amenaza de trascendentalización intenta ser conjurada a través de una percepción del acto de lectura como un proceso de subjetivación y la concepción del texto desde una perspectiva relativista. ¿Qué sucede con la amenaza de anarquía interpretativa?

La definición de reatribución que propone Bayard perfila ya con cierta ironía ("diferente al que generalmente se ha atribuido") la arbitrariedad detrás del nombre de autor. Bajo esta mirada, la crítica de reatribución no es una propuesta con fines estrictamente críticos; antes bien, se trata de una operación estratégica de teorización del autor que parece socavar la fundamentación que éste ofrece al acto crítico.

La tarea de atribución errónea propuesta por Borges había sido anteriormente ponderada por Alexander Nehamas en un sentido que resulta aquí pertinente. En su artículo "Writter, Text, Work, Author" (1987) afirma que el escritor construye un texto que al ser interpretado como obra da lugar a la generación de una figura de autor. En otras palabras, el autor es, como ya lo señalaba Foucault, posterior a la obra y diferente al escritor. Pero su posterioridad se establece en la medida en que es resultado de una operación interpretativa. Por ello, no hay para Nehamas, en principio, ninguna razón lógica por la cual se pueda negar la posibilidad de llevar a cabo una atribución errónea: "Si el autor es nuestro producto, ¿por qué no producir cualquiera que queramos independientemente de cualquier texto en particular?" (1987, p. 284). Sin embargo, Nehamas presenta reparos al sostener que, aunque lógicamente posible, no por eso resulta viable. El esfuerzo implicaría leer un texto no solo en relación al nuevo autor sino también a los demás textos que se le atribuyen a él, lo que conduce a una reformulación de la historia de la literatura. En el marco de un esquema de la comunicación pragmática, Nehamas señala que "el autor debe ser construido como una variante históricamente plausible del escritor, como un personaje que el escritor podría haber sido" (p. 285). En otras palabras, reemplaza la pregunta foucaultiana "iqué importa quién habla?" por esta otra: "qquién puede estar hablando?".

Esta verosimilitud histórica está detrás de la arbitrariedad lógica del autor y se construye como una argumentación pragmática que 
regula la deriva interpretativa: el autor es arbitrario, pero no cualquier autor es válido de igual manera. Primero, porque aunque lógicamente posible, es inviable una reformulación del autor en los términos de una atribución errónea; segundo, porque hay una exigencia de plausibilidad histórica que delimita la arbitrariedad. Estos dos reparos deberían ser considerados a la luz de la crítica de la reatribución de Bayard. Para ello, será pertinente profundizar en un caso particular: Hamlet, de... ¿quién?

\section{Hamlet, de...}

Al señalar el impacto que la propia obra tiene sobre el nombre de autor y considerando que este nombre es a su vez organizador de los modos de ser de la obra, Foucault ejemplificaba en su conferencia de 1969 lo siguiente:

Si descubro que Shakespeare no nació en la casa que hoy se visita, tenemos ahí una modificación que, evidentemente, no va a alterar el funcionamiento del nombre de autor; pero si se demostrara que Shakespeare no escribió los Sonetos que pasan por suyos, tenemos ahí un cambio de otro tipo: no deja indiferente el funcionamiento del nombre de autor. Y si se probase que Shakespeare escribió el Órganon de Bacon simplemente porque es el mismo autor quien escribió las obras de Bacon y las de Shakespeare, tenemos ahí un tercer tipo de cambio que modifica enteramente el funcionamiento del nombre de autor. El nombre de autor no es, entonces, exactamente un nombre propio como los otros. (1994, p. 797)

El condicional en el ejemplo de Foucault puede no ser hipotético. En efecto, el problema de la autoría de las obras de Shakespeare ha despertado polémica y han existido disputas en torno a quién está detrás de su nombre. Foucault se equivoca en pensar que la modificación de un dato correspondiente al escritor -para el caso, la casa que se visita- es indiferente al funcionamiento del nombre de autor, más allá de la adecuada distinción -que Foucault sostiene ambiguamente- entre escritor y autor. La construcción del autor es un proceso complejo que mantiene con la obra relaciones de mutuo condicionamiento. Si se prueba que el Órganon de Bacon fue escrito por Shakespeare se modifica enteramente el nombre de este último, así como se modifican las tragedias atribuidas a él -en 
la medida en que, como lo señalaba Nehamas, resultará posible, si no necesario, leer intertextualmente el Órganon en el contexto de la obra de Shakespeare. Pero si se prueba además que Shakespeare no nació en una casa de Stratford-upon-Avon sino en un castillo de Essex, el nombre de autor cambia en la medida en que también lo hace su obra.

En 1920, Thomas Looney publicó un libro titulado Shakespeare identified in Edward de Vere, the seventeenth Earl of Oxford, con la polémica hipótesis de señalar al decimoséptimo conde de Oxford, Edward de Vere, detrás del nombre de Shakespeare. Según se advierte en su correspondencia, Freud tomó contacto con este libro en 1922 y llegó a estar completamente convencido de la tesis de Looney, a la que defendió con ahínco, molestándose incluso con Ernest Jones cuando éste último -el shakesperiano entre los psicoanalistas- se mostró resistente a considerarla veraz (Jones, 1957, p. 429). Tiempo después, refiriéndose a un ensayo de G. H. Rendall que transitaba el mismo camino -Shakespeare's Sonnets and Edward De Vere (1930)- Freud afirma incluso que "los sonetos se vuelven mucho más entendibles" a la luz de esta hipótesis (citado en Jones, 1957, p. 455).

Pero ¿por qué Freud defiende con tanta convicción la tesis de Looney? Al trabajar sobre el caso de la autoría de Hamlet en Et si les oeuvres changeaient d'auteur ?, Bayard ofrece una respuesta. La vida de Edward de Vere, decimoséptimo conde de Oxford, contiene elementos que compatibilizan con la lectura edípica que Freud hace de Hamlet: perdió a su padre de niño y su madre se casó apenas poco tiempo después de enviudar. Este autor se adecúa mucho mejor a la teoría de Freud que el desconocido Shakespeare de Stratford. A Freud le interesa Edward de Vere porque su figura de autor fortalece su interpretación edípica de la tragedia. La reatribución a la que adhiere Freud parece estar dotada, para recuperar los términos de Nehamas, si no de "verosimilitud histórica", al menos sí de "verosimilitud psicológica". La biografía de Edward de Vere y la tragedia de Hamlet se involucran así en una relación intertextual operada por el propio Freud que condiciona la interpretación de la obra. Ésta última, a su vez, no podría ser entendida tal como aquí la pensamos como posterior o anterior al autor, como su resultado o su causa; antes bien, el autor es una parte de la obra. 
Nos situamos aquí en la pregunta por la topografía de la obra y el lugar que ocupa el autor. En "Auteur et littérarité", Vincent Jouve (2008) distingue cinco formas en las que se ha teorizado el autor cuyas diferencias podríamos pensar a partir de su lugar de ubicación en el universo de la obra: 1) el autor real, propio de la crítica biográfica como la que se expresa en Sainte-Beuve o en M. Bonaparte; 2) el narrador extradiegético, instancia ficticia que representa al autor real en el texto; 3) el autor implicado, entendido por W. Booth (1983) como la imagen del autor tal como puede ser construida por el lector a partir del texto; 4) la figura del autor, noción propuesta por Couturier en los siguientes términos: "no es un personaje de ficción como lo sería un narrador heterodiegético o un autor implicado sino un enunciador singular que, a pesar de sus evasiones, es una proyección parcial del autor mismo" (1995, p. 132); y también: "es un lugar enunciativo al mismo tiempo que un sujeto de enunciación reconstituido por el lector en su acto de lectura" (Jouve, 2008, p. 5); 5) la imagen del autor, categoría ofrecida por el propio Jouve: "la idea que un lector se hace del autor (real) de un libro antes de leer" (2008, p. 6). Estas cinco teorizaciones avanzan desde un abanico que va del escritor al lector empírico, de tal manera que los extremos postulan un autor situado por fuera de la obra, mientras que el autor implicado y la figura de autor parecen el resultado de una transacción dialéctica entre el autor y el lector cuya arena de diálogo es el texto. Así, evocando la propuesta de Booth, Matthieu Vernet señalaba en "L'auteur en soupçon : déjouer la fiction d'autorité" que el lugar privilegiado del autor se sitúa en el espacio fronterizo del paratexto: "Fuera del texto y no fuera de la obra, el paratexto es el lugar de expresión de un yo ambivalente, a medio camino entre el escritor y el narrador" (2011, p. 105).

Estos modos de entender al autor y su relación con la obra problematizan el estatuto mismo de ésta última. La dificultad no es ya solo responder la pregunta por la identidad de Shakespeare sino también por la identidad de la obra Hamlet, en la medida en que una y otra están inter-determinadas, en cuanto sus límites son de difícil establecimiento. No sólo "¿quién escribió Hamlet?" sino también "¿qué escribió Shakespeare?". 
El entramado entre el quién y el qué resulta particularmente evidente en la postura radicalizada de un teórico como Norman Holland, verdadero promotor en los lejanos 60 de una original crítica psicoanalítica orientada a la recepción cuyas huellas es posible identificar en la ensayística de Bayard.

En un artículo de 1975, titulado significativamente "Hamlet -My Greatest Creation", Holland comienza preguntándose por la autoría de esta obra. Sin embargo, pronto advierte que para responder el interrogante se presenta la dificultad de la identidad de la propia tragedia que busca ser atribuida a un autor. ¿Qué escribió Shakespeare cuando nos referimos a Hamlet? Si nos remitimos solo a la construcción del personaje, en los cuatro siglos que han pasado desde su publicación hasta nuestros días, Holland percibe tres personajes-Hamlet diferentes:

El Hamlet de los siglos XVII y XVIII, cercanos al mismo Shakespeare, era un joven de gran expectativa, prometedor, vivaz, un príncipe renacentista. El siglo XIX disfrutó del Hamlet de Goethe: un joven poético, esbelto, delicado, incapaz de llevar a cabo la venganza que su padre demanda. Y, por supuesto, tenemos el Hamlet edípico del siglo XX. Pero no es solo que cada siglo ha tenido su propio héroe y su propia obra. Si miramos los volúmenes sobre volúmenes de comentarios sobre la tragedia, nos daremos cuenta de que, finalmente, cada persona tiene su propio Hamlet. (1975, p. 28)

¿Qué creó entonces Shakespeare?

La respuesta de Holland parece bastante radical y por momentos acude a expresiones como "materiales en bruto". O bien, según una expresión empleada en Poems in Persons (1973) que ya evocamos en la introducción: "un poema, tomado de una manera puramente objetiva, no es más que manchas de carbón negro en pulpa de madera seca" (p. 2). El material en bruto, las palabras sobre la hoja que Shakespeare escribió, deviene en la creación de Hamlet por parte de un acto perceptivo del lector. A diferencia de las perspectivas provenientes de la estética de la recepción alemana -resistentes a todo psicologismo-, Holland subraya el papel que cumple la identidad del lector en el proceso de la construcción de la obra y perfila la hipótesis de que la lectura es una búsqueda de recreación de la propia identidad. Ésta última es definida como la invariante que se puede 
abstraer de todas las decisiones del yo en la vida de un individuo, siendo la percepción una de esas decisiones. Así, los lectores usan los materiales del texto de un modo particular y "cada uno de nosotros crea su propio Hamlet a partir de las palabras que Shakespeare nos ofrece" (Holland, 1975, p. 30).

En consecuencia, Holland puede afirmar que Hamlet ha sido su mejor creación. Han sido esas manchas de carbón negro en pulpa de madera seca atribuidas a un tal Shakespeare las que le han permitido -o más bien, con las que mejor ha logrado- recrear su propia identidad. La lectura deviene escritura, Hamlet su propia obra, y el lector deviene autor.

La radicalidad en la posición centrada en el lector que asume Holland es sin embargo ambivalente a lo largo de su pensamiento. A Holland le resulta muy dificultoso resolver el problema epistemológico de cómo el lector accede a un contenido del texto y cómo puede producir sentido a partir de "manchas de carbón negro". Este problema está encadenado a la necesidad de mantener la noción de identidad como sustituto de la intencionalidad -ya sea del autor, ya del lector.

En 1985, al revisar en The I la manera en que había presupuesto los conceptos de autor y texto en un trabajo temprano de 1966 titulado Psychoanalysis and Shakespeare, Holland sostiene que:

El libro continuaba mi estudio de los textos como palabras en la página, aislables y objetivas; pero el último capítulo socavaba los límites fijos con que los críticos de ese entonces separaban autor, texto y lector. Yo propugnaba, más bien, que la transacción literaria forma un continuum. (1985, p. 285)

¿Qué es entonces ese autor que forma parte del continuum de la transacción literaria? ¿Cómo se integra en el proceso de la lectura? ¿Tiene el mismo estatuto que el texto? Es decir, ¿puede considerarse como una materia prima a partir de la cual trabaja el lector? ¿La existencia de una psiquis y, por tanto, de un tema identitario en un supuesto autor empírico vuelve diferentes las naturalezas del texto y del autor en el momento de la experiencia de lectura?

Los diversos trabajos de Holland no son capaces de responder adecuadamente estas preguntas que ponen en evidencia contradicciones que resultan del intento de convivencia entre una crítica 
orientada al lector, una perspectiva de la obra como unidad orgánica y una oposición a todo pensamiento que insinúe la desaparición del sujeto (que Holland cree entender como sinónimo de Hombre). En Poems in Persons, por ejemplo, es notable la dificultad en el abandono de la "psiquis del autor": Holland intenta reconstruir la identidad de la poetisa Hilda Dolittle para explicar su obra, aun cuando simultáneamente se afirma la condición epistemológica de percepción de la literatura a través del lente identitario del lector. Por otro lado, si bien un lector con biografía, historia y psicología -opuesto así a aquel que presupone Barthes en "La mort de l'auteur"- viene a ocupar el lugar del autor y desplazarlo, Holland todavía intenta conservar el principio de unidad tan importante para la Nueva Crítica. Si el autor se abandona, el lector toma su lugar como principio unificador y estabiliza de esta manera el sentido. Si Holland incluye el sujeto del inconsciente en la lectura, su posición se mantiene en el marco de una perspectiva hermenéutica del texto. Los conceptos de identidad y de yo, vinculados a la psicología del yo a la cual adhiere, tienden a recobrar la estabilidad perdida en el momento en que el autor deja de ser un centro unificador y regulador. Si no hay una conciencia autoral a la cual subordinar la obra, Holland, operando una aparente descentralización del sentido, sostiene la unidad y estabilidad del texto a través de la identidad y el yo del lector.

Norman Holland inaugura una senda en la teoría de la lectura en la que podemos ubicar años después a Bayard: ambos despliegan una posición orientada al lector desde un fundamento psicoanalítico que condiciona epistemológicamente el estatuto de la obra. Sin embargo, sus posiciones se distinguen en el modo en que asumen una perspectiva relativista o hermenéutica del texto y en la medida en que se apropian de una manera diferencial del psicoanálisis.

Ambos trabajan inversamente respecto a la hermenéutica y el relativismo. Holland, apelando a un relativismo, permanece sin embargo dentro de una concepción hermenéutica en la medida en que, aunque declara abandonar al escritor, se preocupa por inscribir en el texto un sujeto que garantice la unidad orgánica de la obra a la vez que no descarta la psiquis del autor como referencia. El segundo, en cambio, sobre una aparente posición hermenéutica inscribe al autor en el texto para desplazarse hacia una perspectiva relativista 
que lo desestabiliza por la misma operación de inscripción. Con esto, Bayard procura conjurar una concepción trascendental de la experiencia literaria. La obra es pensada en el marco de un proceso de subjetivación que no se reduce a una identidad tal como la entiende Holland.

¿Cómo se entrama el qué y el quién en el caso de Bayard y cómo se configura una posición diferencial respecto a la de Holland? ¿Qué lugar ocupa el autor en la cartografía de la obra en el pensamiento del crítico francés? Podemos volver a la pregunta: "iquién es Shakespeare?". Este interrogante no remite al enigma biográfico, sino al estatuto mismo del referente, a la condición de ser del autor, atravesado por las complejidades topográficas a las que venimos aludiendo: "cuando pronunciamos un nombre de autor -dice Bayardy decimos por ejemplo 'Shakespeare', designamos en realidad cada vez tres referentes distintos, que se superponen y confunden, a veces al interior de la misma frase” (2010, p. 38). ¿Cuáles son estos tres referentes?: 1) el autor real: la persona física detrás de la obra que ha vivido una época, que es históricamente situable, "el hombre"; 2) el autor interior: un "yo interior o profundo" que pone en juego la crítica literaria, aquel del que habla Freud al referirse al autor de Hamlet: "el creador"; y 3) el autor imaginario:

ni el autor real ni el interior nos son accesibles directamente, porque son extensamente producidos por el lector y la época a la que pertenece, sus preocupaciones, sus modelos de pensamiento [...] Este autor imaginario omnipresente, que implica todas las imágenes y los fantasmas [fantasmes] que podemos desarrollar a propósito de un autor, nos impide un acceso real al escritor y, lo que es aún más grave, a su obra. (2010, pp. 38-39)

La tríada autoral propuesta por Bayard no se despega en apariencia de lo que ya suponía Holland, quien incluso dejaba entender que toda identidad autoral construida resulta de un proceso transaccional con la identidad del lector. El autor real y el autor interior son inaccesibles para el conocimiento: cuanto sabemos de ellos está permeado por la construcción imaginaria que producimos como lectores. Pero a diferencia de Holland, el autor imaginario de Bayard se apoya en una concepción teórico-epistemológica que subvierte la noción de unidad y acentúa el carácter de acontecimiento del 
acto de lectura mediante una concepción del sujeto completamente diferente.

La noción de autor imaginario pone en evidencia dos argumentos presentes ya en la conferencia de Foucault, pero trabajados aquí desde una perspectiva psicoanalítica de corte lacaniana: por un lado, se cuestiona la exterioridad del autor respecto a la obra, siendo el autor imaginario un producto textual, en cuanto resultado del fantasma del lector; por otro lado, el autor imaginario en cuanto parte del texto afecta la constitución de su sentido. De esta manera, la noción de autor de Bayard se acercaría a aquella de Holland; pero a diferencia de este último, asume el vínculo que une el sujeto con el significante y constituye un sujeto de la lectura habitado por un hiato que no puede resolverse en una supuesta identidad orgánica -ni del lector (incluida su construcción imaginaria de autor) ni de un supuesto autor empírico (autor real)-. La unión del sujeto con el significante implica la construcción de una conceptualización de la obra -autor incluido- como resultado de un acontecer de la lectura perpetuamente fallido. Como en Holland, la lectura deviene escritura, Hamlet su propia obra, y el lector deviene autor. Pero en Bayard la escritura no cesa, la obra como unidad orgánica está fracturada por una falta y la identidad es siempre una promesa por venir. Este modelo ofrece un nuevo modo de encarar las preguntas sobre el qué y el quién de la escritura.

\section{Los siete pilares de la sabiduría y El amante de Lady Chatterley, de Pierre Bayard}

En la medida en que el autor está atravesado por el fantasma del lector, para Bayard "todo nombre de autor es una ficción [...] todo nombre de autor es una novela" (2010, p. 27).

El autor no sería un elemento exterior al texto que nos permitiría estabilizarlo, unificarlo y legitimar una lectura excluyente. Pero de ninguna manera esto significa descartarlo. El autor es un elemento textual más en el universo ficcional de la obra. Como tal, está construido por el lector y depende de las relaciones que establece con los demás elementos del texto. A la vez, tampoco podríamos pensar que el autor es un personaje como cualquier otro, ni podríamos 
atribuirlo a una intención autoral implícita en el texto. El autor es en Bayard una novela construida por el lector a partir de la cual se establecen relaciones intertextuales. ${ }^{4}$

Así, en el momento en que Bayard atribuye a L. Tolstoi Lo que el viento se llevó, la lectura de esta novela se condiciona no solo por las características biográficas del autor imaginario "Tolstoi" que hay en el lector Bayard. Lo que el viento se llevó adquiere a su vez relaciones intertextuales con otras obras del escritor ruso. Relaciones que se establecen en el acto de la lectura y permiten leer esta novela como una reflexión sobre la desaparición del mundo de la infancia. Este ejercicio de reatribución es posible mediante el uso estratégico de la teoría ficcional, capaz de proponer un anacronismo semejante. ${ }^{5}$

El modo en que el autor se inscribe en la obra a través del lector en la crítica de Bayard se evidencia con particular claridad en el capítulo de Et si les oeuvres changeaient d'auteur ? titulado "Los siete pilares de la sabiduría de D. H. Lawrence y El amante de Lady Chatterley de T. E. Lawrence". El título sorprende por la inversión autoral producida, en cuanto ha sido T. E. Lawrence el autor de la primera novela y D. H. Lawrence el de la segunda. Pero sorprende también porque se trata de dos novelas y dos autores verdaderamente opuestos, tanto en sus escrituras y temáticas como en sus biografías. Aun así, Bayard considera que esta oposición debe ser superada:

Es posible que los dos libros, si se hace el esfuerzo de no considerarlos de manera aislada y de vincularlos a sus creadores para comprenderlos mejor, cuenten una historia idéntica más allá de sus diferencias superficiales. Una historia que concierne a una de las preguntas teóricas más viejas de la literatura, a saber, la manera en que la sexualidad se inscribe -o, al contrario, no llega a inscribirse- en las profundidades de la escritura. (2010, pp. 103-104)

4 En Bayard la noción de intertextualidad parece estar usada en el sentido amplio que le da Gérard Genette: "relación de copresencia entre dos o varios textos" (1982, p. 8).

5 Es pertinente señalar aquí que Bayard publicó a finales de 2017 -de manera posterior a la escritura de este artículo- un ensayo titulado L'énigme Tolstoïevski, donde lee diversas obras de Tolstoi y de Dostoievski a la luz de la biografía de un autor imaginario llamado Tolstoïevski. Considerando la poca información que habría sobre este autor, Bayard pondera sin embargo que "incluso cuando nos referimos a creadores sobre los cuales abunda la información, estamos hablando en realidad de personas ficcionales, como es el caso del Leonardo da Vinci imaginario que permitió a Freud, sobre la base de una ilusión creadora, elaborar su teoría de la sublimación" (Bayard, 2017, p. 19). 
Al igual que Barthes, Bayard cuestiona las perspectivas que, como la psicobiografía, vinculan la obra al autor como fuente de autoridad del sentido. Pero a diferencia de Barthes -el de "La mort de l'auteur"-, la estrategia de Bayard consiste en subrayar la importancia del escritor para la comprensión de la obra. No aboga por descartar el autor, pero en el momento en que afirma la necesidad de considerarlo, lo concibe al interior de la obra y como efecto de un acto de lectura. Operación que conduce a preguntarse quién, en realidad, cuenta aquella idéntica historia.

El amante de Lady Chatterley (2012) describe las relaciones sexuales que una mujer aristócrata casada mantiene con un obrero. Lo que intriga a Bayard, en una operación irónica de reatribución, es cómo es posible que un escritor como T. E. Lawrence, célebre por su puritanismo, haya sido capaz de concebir esta novela. Pero, ¿quién es el autor de esta obra que lee Bayard? El crítico francés señala que el lenguaje procaz y la temática sexual de la novela llevaron "al escritor a un proceso judicial por buenas costumbres” (2010, p. 104). Por otro lado, lee la obra a través de la hipótesis de una homosexualidad "al menos latente" de T. E. Lawrence. Finalmente, describe a éste último como un "personaje puritano" y como un "militar rígido" (p. 106).

Ciertamente, estas dos últimas caracterizaciones coinciden con la descripción que los trabajos biográficos suelen hacer sobre T. E. Lawrence. ${ }^{6}$ Pero no sucede lo mismo con el proceso judicial al que alude Bayard. A la vez que sería necesaria cierta cautela en torno al empleo de la homosexualidad del militar inglés como clave de lectura: si seguimos algunas biografías, lo que parece evidente es su desagrado hacia las relaciones carnales. ${ }^{7}$ El dato del juicio e incluso la consideración de una homosexualidad latente entran en diálogo con D. H. Lawrence, signatario de todas las ediciones existentes de El amante de Lady Chatterley, obra que en 1960 fue blanco de un proceso judicial por atentar contra las buenas costumbres.

Lo que hace Bayard, pues, no se limita a una reatribución. Porque toma un elemento biográfico de D. H. como la homosexualidad y la involucra en la biografía de T. E.: interpreta así el rechazo por

6 Cfr. Ocampo (2013), y Stewart (1977).

7 Cfr. el capítulo "Homosexualidad" en Ocampo (2013). 
lo carnal como deseo homosexual. Pero fundamentalmente porque adjudica a T. E. un proceso judicial que ocurrió en realidad contra la editorial Penguin en 1960, momento de la edición de bolsillo del libro, treinta años después de la muerte de $\mathrm{D}$. H. Se percibe así que Bayard, sin declararlo explícitamente, lleva a cabo una operación más compleja que la simple reatribución, y termina por construir un autor imaginario híbrido, que tiene aspectos biográficos pertenecientes a la biografía de T. E. ("personaje puritano" y "militar rígido") pero que adquiere también elementos tanto de D. H. ("homosexualidad latente”) como de la propia obra (el juicio de 1960). En efecto, el juicio que inicia el Tribunal Penal Central de Inglaterra y Gales es contra la editorial Penguin ("Regina v. Penguin Books Ltd.") $)^{8}$ en el momento de publicación de la novela en su edición de bolsillo. Pero es necesario admitir que este juicio, junto al escándalo producido, tiene un impacto sobre la lectura, inscribiéndose en la obra: hecho que se vuelve evidente por el éxito editorial que la novela tuvo luego del juicio.

Advertimos así el modo en que Bayard construye en este caso un autor imaginario heterogéneo, compuesto de elementos provenientes de dos autores empíricos y de un acontecimiento editorial, que impacta sobre la manera en que se leerá la novela.

Otro tanto sucede con Los siete pilares de la sabiduría (1989), donde la obra, reatribuida a D. H. Lawrence, es leída en relación intertextual con otras novelas como La serpiente emplumada o Hijos y amantes. De manera que la operación de reatribución no es idéntica en cada caso y presenta aspectos diferentes del problema del autor.

En el caso de El amante de Lady Chatterley la construcción del autor imaginario es más compleja y la interpretación de Bayard impacta más sobre el autor que sobre la novela -en la medida en que esta separación es posible-. La novela es leída como el relato de una historia sobre la manera en que la sexualidad se inscribe en la escritura. Bayard no busca justificar esta lectura que le parece evidente (puesto que la sexualidad está allí presente al punto de haber

8 La editorial Penguin publicó en 1961, con edición de C. H. Rolph, extractos de la fiscalía y de la defensa con el título Lady Chatterley's Trial. A partir de esta transcripción sostenemos el argumento de contra quién se desarrolló el juicio (Rolph, 2005). 
suscitado un proceso judicial); le interesa explicar cómo es posible que un autor del perfil de T. E. Lawrence haya podido escribirla. En consecuencia, se ve conducido a elaborar una hipótesis de lectura sobre el autor que explique el vínculo entre semejante novela y tan aparente antagónico escritor, un poco como Freud se ve llevado a hacer una hipótesis sobre la identidad del creador de Hamlet:

Todo lo que sabemos de la vida y de la personalidad de ese militar rígido nos incita a imaginar que la sexualidad era en su vida personal el objeto de un profundo rechazo. No es por lo tanto sorprendente, por poco que uno se sitúe en una lógica freudiana, que esta sexualidad rechazada, largo tiempo contenida, haya encontrado finalmente libre curso en un libro donde se le ha dado la posibilidad de desahogarse libremente, atribuyéndola a otros antes que a sí mismo. (2010, pp. 106-107)

Lo que está en el centro de la escena de la novela, según lee Bayard, es una fascinación por el goce femenino, el lugar de la mujer como enigma. Esta lectura conduce al crítico francés a interpretar una identificación secreta del autor británico con la protagonista de la novela: "Para quien conoce la homosexualidad, al menos latente, de T. E. Lawrence, es difícil no adivinar un desplazamiento de esta índole detrás de la pintura del goce femenino" (2010, p. 107). Ciertamente, el conocimiento de la homosexualidad, "al menos latente", implica una interpretación que es posible en Bayard por la cercanía que establece con D. H. Lawrence y por una lectura psicoanalítica de la novela. Puesto que, si seguimos en esto el agudo ensayo de Victoria Ocampo a propósito del escritor británico, es más el ascetismo asexuado que la homosexualidad lo que parece caracterizar a T. E.: "Lawrence ve en las mujeres o bien seres humanos dignos de recibir su amistad asexuada, al mismo título que un hombre, o bien hembras codiciadas por machos, trampas de la lujuria [...]. Lujuria que exacerbaba su desprecio y asco de la carne" (Ocampo, 2013, p. 73). Bayard necesita elementos de la novela y de la biografía de D. H. para acentuar el carácter homosexual de T. E. que le servirá de clave de lectura.

En el caso de Los siete pilares de la sabiduría, esta doble interpretación que involucra el goce femenino por un lado y la frustración por el otro se presenta igualmente aunque su vía de aparición toma otro curso. La reatribución funciona como conducto hacia relaciones intertextuales con otras novelas de D. H. Es la presencia 
de la sexualidad en otras obras lo que lleva a leer la sexualidad, en apariencia totalmente ausente, detrás de esta novela, para la sorpresa de cualquier lector de D. H. Lawrence: "Que [la sexualidad] no esté en primer plano como en otros libros de Lawrence no implica que haya desaparecido. Al contrario: impregna incluso cada página de Los siete pilares, y es bastante fácil reconocerla, a condición de saber identificar sus marcas discretas" (2010, p. 109). Bayard encuentra estas marcas en la relación que mantienen los hombres en el combate, cargadas de erotismo y sadomasoquismo.

La interpretación de las dos novelas, entonces, conduce a un destino similar, a pesar de las aparentes diferencias entre ellas, leídas normalmente una en las antípodas de la otra:

Si estamos finalmente, con estos dos textos que se oponen, frente a un mismo texto, donde una temática inconsciente similar es diferentemente declinada -la de la angustia arcaica frente a la sexualidad y lo femenino-, podríamos preguntarnos en qué medida no se trata del mismo autor, que se habría revestido de apariencias diferentes pero que se situaría en un lugar común. (2010, pp. 112-113, los énfasis son míos)

¿Cuál es ese mismo autor? ¿Cuál es este mismo texto? Estos interrogantes nos devuelven al problema del quién y del qué, así como a la manera en que se entraman y condicionan configurando una cartografía de la obra. Respecto a la segunda pregunta, Bayard no tarda en especificarlo al aludir a un supuesto texto universal al que todos los autores llegarían desde puntos diferentes y del que no serían más que escritores de paso. Sin embargo, creemos posible responder, a partir de Bayard, de otra manera estos interrogantes para acceder así a una conceptualización específica del autor.

El mismo texto que Bayard lee en estas novelas -pero también en otras que analiza a lo largo de sus ensayos- señala cierta coincidencia con la idea de identidad de Holland, para quien cada lector leerá siempre una misma obra puesto que repetirá su tema identitario y su estilo personal. En coherencia con esta posición, es posible advertir repeticiones en las lecturas de Bayard, quien parece interpretar los mismos tópicos en todas las obras. Los dos más recurrentes son la sexualidad (tanto en las obras en las que aparece explícitamente como en aquellas que demandan una elaboración interpretativa del crítico) y la identidad (es decir, el problema de los límites entre el yo y el otro, entre el afuera y el adentro). 
Sin embargo, no se trataría de una recreación de la identidad del lector tal como se concibe en Holland; la noción que en Bayard parece estar detrás de la repetición es la de libro interior desarrollada en Comment parler des livres que l'on n'a pas lus? (2007), y que nos sirve para leer sus propias operaciones de lectura: "conjunto de representaciones míticas que se interponen entre el lector y todo nuevo escrito, y que modelan la lectura a sus espaldas" (2007, p. 81). Se trata de un libro imaginario ampliamente inconsciente que "determina la recepción de nuevos textos al decidir qué elementos serán retenidos y cómo serán interpretados (p. 82). Más adelante, completa la definición señalando que está "tejido por los fantasmas propios de cada individuo y de nuestras leyendas privadas" y que "actúa en nuestro deseo de lectura, es decir, en la manera en que buscamos y luego leemos libros" (p. 83). Para rematar posteriormente: "Es ese objeto fantasmático en busca del cual vive todo lector y del cual los mejores libros que encontrará en su vida no serán más que fragmentos imperfectos que le incitan a continuar leyendo" (p. 83).

El acto de lectura es por lo tanto un intento fallido de escritura de un libro tejido por los fantasmas de cada lector. A diferencia de la identidad, el concepto de libro-interior supone la repetición resultante de un juego entre aquello que Lacan nombra en el Seminario XX $l_{o}$ que no cesa de no escribirse y lo que no cesa de escribirse. A diferencia de Holland, Bayard descubre una imposibilidad en la lectura que deviene escritura: una imposibilidad ligada a la reconstrucción de esa identidad unitaria del lector que no cesa de no escribirse. El librointerior está en el deseo de la escrilectura y configura como resultado un autor deseado. No un deseo del autor -que el lector, como plantea Couturier (1995), debería buscar para recomponer el texto en función de la figura del autor, es decir, de su deseo de expresarse- sino un deseo de autor: esto es, un autor imaginado fantasmáticamente por el lector a la vez que un deseo de devenir autor.

En la estela barthesiana de una textualidad vinculada a la clausura de la representación -según John Burke, el verdadero tema del que habla Barthes en "La mort de l'auteur"-, Bayard puede sin embargo (quizás, si seguimos con Burke, por razones coyunturales o estratégicas que justificaban la muerte del autor en Francia a fines de $\operatorname{los} 60$ y la hacen ahora innecesaria) dar lugar a un sujeto con 
historia, biografía y psicología. Pero este sujeto no puede pensarse en el marco de una psicología del yo como la que despliega Holland sin caer en una trascendentalización de la experiencia literaria; antes bien, estamos con Bayard frente a una subjetividad que ocurre cada vez durante el acto de lectura, como un acontecimiento singular -valga la redundancia- entendido en términos de proceso paradójico de aparición y desaparición simultáneas cuya conceptualización procura evitar toda sustancialización.

La operación de reatribución produce irónicamente una centralización sobre un autor reasignado que no es sino un descentramiento de la lectura clásica que busca en el autor el punto estabilizador del significado y unificador del texto. En lugar de este autor, Bayard construye un lector deseante de volverse autor, un sujeto de la lectura múltiple y escindido, incapaz de clausurar la fantasía orgánica de la psicología del yo.

Volvamos, entonces, a las preguntas que iniciaron este apartado. ¿Cuál es ese mismo texto? Es aquel que pretende escribir cada vez el inconsciente del sujeto de la lectura, según la determinación del libro interior; es la operación imposible, hemorrágica, de su escritura, en tanto el yo es a su vez un tejido de citas, un injerto sobre el texto leído. ¿Cuál es ese mismo autor? La expresión mismo autor -que Bayard utiliza para referirse a una supuesta convergencia en un mismo sujeto de los nombres de T. E. y D. H. Lawrence- es una estrategia que emplea la ironía para anunciar que el lector es una y otra vez el mismo autor de los mismos textos que lee. Un autor que no cesa de no escribir un libro interior. ${ }^{9}$

La noción de autor así pensada se desdobla: por un lado, el lector devenido autor, es decir, el crítico; por otro, el autor como figura ficcional que resulta como efecto de la intervención del crítico,

9 Parece oportuno evocar nuevamente aquí el ensayo L'éngime Tolstö̈evski al que hicimos alusión en una nota anterior puesto que la idea de mismo autor, que buscamos rastrear a partir de la homonimia de los dos escritores Lawrence, se configura ahora de una manera todavía más explícita y radical al elaborar un acrónimo formado por los nombres de Tolstoi y Dostoievski. Bayard construye así una novela biográfica desarrollada en la primera parte de su ensayo y a partir de la cual interpretará obras como La guerra y la paz o Crimen y castigo. No se trata ya de leer las novelas de uno de los Lawrence a partir la biografía del otro (alterando igualmente, como vimos, la biografía de cada autor); se trata ahora de crear explícitamente un autor imaginario cruzando las biografías de los dos autores. Una operación que procura avanzar, nuevamente, en la idea de que más allá del juego irónico todo autor es una construcción imaginaria del lector. 
la novela biográfica. En la configuración de esta novela se advierte el juego de descentramiento que opera Bayard: sin anularlo en el proceso interpretativo, el autor se convierte en un efecto de lectura que actúa intertextualmente con la obra -desde una suerte de paratexto ficcional, borde que no está ni dentro ni fuera de la obra, ni personaje ni imagen.

Cuando Bayard habla de reatribución está desplegando una crítica a la interpretación hermenéutica que parece aún persistir en la resurrección del autor presente en los estudios culturales. Por eso es que, en un ensayo tan centrado en el autor, es posible que Bayard afirme que:

Se advierte así el interés, en la lectura de una obra, en no abordarla con prejuicios ideológicos, sino leerla como una producción autónoma, esforzándose en olvidar lo más posible todas las informaciones demasiado reconocidas sobre el autor, para evitar que la mirada sea deformada por un exceso de conocimientos biográficos. (2010, p. 135)

\section{Leer contra el autor: el autor como argumento}

En 2009 -un año antes de Et si les oeuvres changeaient d'auteur ?-, Bayard publicó un libro escrito con el mismo espíritu titulado Le plagiat par anticipation: trabajo en el que sostiene la hipótesis según la cual la historia literaria no corre siempre en la misma dirección, de modo tal que es posible pensar en casos de plagios ocurridos de manera inversa al tiempo cronológico. El plagio por anticipado se revela como una estrategia de ficción teórica que, a través de la ironía, permite revisar la concepción tradicional de la historia literaria así como la noción de influencia a ella vinculada. ${ }^{10}$ Esta revisión lleva a pensar que no todo escritor puede ubicarse en la historia literaria siguiendo los parámetros de la historia evenemencial. ${ }^{11}$ En este marco, Bayard propone leer al novelista inglés Laurence Sterne desde la influencia de James Joyce y del nouveau roman, considerando más

10 En "La lectura del tiempo en la obra de Bayard" (Garayalde, 2018), he efectuado un análisis del concepto de historia literaria que se desprende del libro Le plagiat par anticipation, atendiendo las tensiones y diálogos que mantiene con el pensamiento de autores como Harold Bloom y Hans Robert Jauss.

11 La noción de historia evenemencial como serie cronológica de acontecimientos -propuesta por Paul Lacombe y François Simiand- se distingue así de la historia literaria como elaboración lógica de las relaciones entre obras y autores. Fernand Braudel la define en estos términos: "una agitación de superficie, las olas que las mareas levantan con su poderoso movimiento" (1993, p. 17). 
adecuado ubicar su obra y su vida en la segunda parte del siglo Xx. La reformulación de la historia literaria obliga así a una reescritura de la biografía del autor: sin ejercer una reatribución, Bayard pone en evidencia sin embargo el carácter ficcional que constituye al autor. En consecuencia, propone una biografía nueva de Sterne para una nueva historia literaria:

Laurence Sterne: novelista inglés (Clonmel, Irlanda, 1913 - Londres, 1968). Hijo de un oficial de la armada inglesa, estudió en Cambridge y se desempeñó como pastor de Sutton-on-the-Forest, donde llevó una vida retirada durante 20 años. En 1959, publicó su primera novela, Vida y opiniones del caballero Tristram Shandy, fuertemente marcada por la influencia de Joyce y de los escritores del nouveau roman francés. Otra de sus obras, Viaje sentimental por Francia e Italia (1968) constituye un precioso testimonio de la vida en Francia. (Bayard, 2009, p. 122)

Ciertamente, el relativismo toca aquí su punto más crítico en cuanto a la arbitrariedad y anarquía a la que puede conducir tal deriva interpretativa. El empuje hacia una teoría de la lectura como acontecimiento en la que el sujeto falla en la escritura de su libro-interior y en la que los límites de la obra se desdibujan por la inscripción del lector conduce rápidamente a las objeciones concernientes a los límites de la interpretación. Bayard parece no preocuparse demasiado por esta amenaza e incluso llega a asociar -en un ensayo dedicado precisamente a Hamlet- la lectura con el delirio, el lire con el délire. Este delirio, sin embargo, no ocurre en un solipsismo autista. En Enquête sur Hamlet (2002), la concepción de la lectura como delirio se ve atemperada, regulada, controlada por la asunción del concepto de paradigma como marco de lectura, solución cercana a la que el pragmatismo de Stanley Fish (1980) ofrece frente a la anarquía interpretativa con la formulación de las "comunidades interpretativas". También en Comment parler des livres que l'on n'a pas lus ? (2007), Bayard ofrece la noción de biblioteca colectiva para dar cuenta del marco textual desde el cual se interpreta. El universo que Bayard piensa para el lector es un universo de libros, en el que tanto el lector como el autor son un libro más, en una fantasía textualista atravesada por una visión psicoanalítica del sujeto.

El mismo año de 2009, el grupo Fabula -compuesto por un conjunto de críticos franceses entre los cuales se encuentra habitualmente Bayard- organizó el seminario "Lecture contrauctorial: problematiques", 
que devino, dos años después, en un conjunto de ensayos reunidos por Sophie Rabau con el título Lire contre l'auteur (2011). La propuesta que subyace a este libro es la de desarrollar un método que lee a contrapié de lo que se supone es la intención autoral. La manera en que esta última es definida resulta de lo más variada en los diversos textos que componen la antología de Rabau: desde la identificación de la intención con lo que el autor ha explicitado en algún paratexto -y según una modalidad propia de la crítica positivista- hasta la consideración de las huellas que la intención deja en el texto -en una visión acorde con la figura del autor de Couturier o con el autor implicado de Booth. El objetivo de tal práctica consiste en liberar el texto de la coacción ejercida por parte de la intención del autor y abrirlo a las virtualidades que tal coacción no permite visibilizar, sin negar por ello la intención. Las objeciones metodológicas que podrían presentarse ante el problema de la identificación de la intención del autor -iqué criterio emplear para definir una intención que se está asumiendo epistemológicamente inaccesible?- se anulan en el costado teórico del planteo: el autor, sea la intención supuesta o la figura construida, es un argumento. Un argumento propio de la hermenéutica a la que la lectura contra-autoral dirige sus ataques. No se trata así tanto de un método -aunque Rabau señale que el objetivo del seminario es proponer un método novedoso- como de un posicionamiento teórico: "La lectura contra-autoral se sostiene más bien en una redefinición del estatus del autor en el acto de lectura a partir de una reflexión sobre la naturaleza del discurso hermenéutico" (Rabau, 2011, p. 14).

Leer contra el autor es además un gesto polémico que, en la línea de la teoría poética de un H. Bloom (1997), percibe una disputa entre lector y autor, una disputa por la escritura que malentiende -para emplear un término de Bloom- el texto para escribir en su lugar, del mismo modo que la reatribución de Bayard -en línea con la atribución errónea de Borges- se sostiene en un "error creativo": "error voluntario de atribución, destinado a hacer aparecer una dimensión oculta de una obra o de un autor" (Bayard, 2010, p. 155).

El error creativo supone una decisión completamente desfundamentada; pero señala a su vez el desfundamento del autor como 
centro en la perspectiva hermenéutica al evidenciar el carácter ficcional y argumental de su ontología. La anarquía interpretativa -amenaza cierta que pesa sobre cualquier decisión en cuanto ausencia de fundamento- no puede ser contestada más que con una retórica de la persuasión: la lectura contra-autoral así como la crítica de reatribución son estrategias argumentales que presentan verdades posibles del texto entendido como acontecimiento literario. Desde el punto de vista de una lectura contra-autoral, la hermenéutica literaria, como la denomina Rabau, no se describe ya como un discurso de verdad que opone verdadero a falso, sino como un discurso que sostiene que la mejor forma de persuasión es la "prueba" del autor y el secreto a develar vinculado a él.

En L'auteur encombrant: Stendhal/Ambrant, Jean Bellemin-Noël (1985) -director, por cierto, de la tesis doctoral de Bayard- señala, contra esta concepción hermenéutica, que "un texto no tiene, no puede tener un secreto: en rigor, es un secreto, que no podrá formularse jamás, que se inscribe como imposible de escribir" (1985, p. 35). El secreto del texto -formulado en Bayard con el nombre de libro-interior- desfundamenta la lectura hermenéutica que busca en el autor un punto de anclaje trascendental y un control sobre la deriva interpretativa. Frente a esta hermenéutica, el relativismo asumido por críticos como Bayard (y otros nucleados alrededor de Fabula) concibe la experiencia de lectura como acontecimiento y resuelve la deriva interpretativa en una posición pragmática: el autor es una novela imaginada cada vez cuyo criterio de validez se dirime en su poder argumental.

\section{Conclusión}

La resurrección del autor -que ya lleva más de cuarenta añostoma en críticos como Bayard y Rabau una orientación hacia el lector como autor de una escritura imposible que pretende dar cuenta del secreto del texto: es decir, del texto como acontecimiento, como aparición y desaparición simultánea de la verdad literaria según la inscripción de un sujeto de la lectura entendido en términos psicoanalíticos. En este marco, el autor resucita como argumento ficcional y como acto y efecto de lectura. 
En Bayard, esto ocurre según una lógica que orbita irónicamente en torno a lo que el crítico francés ha denominado las perspectivas hermenéutica y relativista, procurando conjurar de un lado y otro los problemas que evocamos en la introducción: la amenaza de una concepción trascendental del acontecimiento literario y la amenaza de la anarquía interpretativa.

Por un lado, la crítica de reatribución -como también la crítica contra-autoral- opera recuperando elementos propios de la hermenéutica como la biografía -y la intención- para ser utilizados como clave de lectura. Pero estos elementos son simultáneamente descentrados como fundamento interpretativo: la biografía deriva en una novela de lector; la intención, en una construcción argumentativa elaborada por la interpretación. En pocas palabras, el autor como centro regulador de la interpretación es resultado de un acto singular de lectura. Bayard inscribe así la hermenéutica en una particular teoría de la lectura, de acuerdo con una modalidad que lo separa de otras teorías orientadas al lector evocadas en este ensayo. A diferencia de las teorías de la recepción antipsicologistas inspiradas en la fenomenología -como es el caso de los críticos de la Universidad de Constanza que, como Iser, entienden la experiencia estética a partir de un diálogo de conciencias que ocurre al nivel de la estructura del texto- Bayard recupera el autor a través de la elaboración de un lector psicoanalíticamente definido, constituido cada vez en el acontecimiento de la lectura. A diferencia de teorías de la lectura inspiradas en el psicoanálisis como la de Holland -quien garantiza la unidad de la obra sustituyendo la identidad del autor por la del lector, e incluso conservando finalmente una concepción del autor hermenéuticamente pensada que dialoga transactivamente con el lector-, el crítico francés elabora un sujeto de la lectura entendido como un proceso y no como una identidad. Así, buscando conjurar una concepción trascendental del autor y la obra literaria, la lectura es entendida como un acontecimiento en la que el texto es desestabilizado.

Por otro lado, la amenaza de la anarquía interpretativa que acecha el acercamiento a una concepción relativista parece conjurada desde una posición pragmática que ve en la fuerza retórica y poética -lo que supone, para retomar una expresión de Nehamas, una verosimilitud histórica y psicológica- la regulación de la interpretación (determinada 
por las condiciones de la comunidad interpretativa a la que el crítico pertenece). Podríamos pensar, por lo tanto, que la posición de Bayard se acerca aquí a los planteos de Stanley Fish (1980) en su célebre ensayo Is There a Text in this Class? Tanto para Fish como para Bayard, parece no haber un límite textual a la interpretación, puesto que el texto -y el autor- es posterior a ella (es su resultado) y no a la inversa. Pero esa es una verdad, como diría Fish, que no debe alarmar a los espíritus preocupados por la anarquía interpretativa. En primer lugar, porque el relativismo es una posición que uno puede sostener, pero no una que se pueda ocupar: "Nadie puede ser un relativista, porque nadie puede lograr una distancia respecto a sus propias creencias y supuestos que daría como resultado que no sean para esa persona una autoridad mayor que las creencias y supuestos sostenidos por otros" (1980, p. 319). Así como para Fish la "comunidad interpretativa" regula que no cualquier cosa pueda ser dicha acerca de un texto (cuya existencia objetiva Fish ponía en cuestión), en Bayard esta misma regulación se establece a través del paradigma y la biblioteca colectiva a los que pertenece el lector. En segundo lugar, porque si bien no existe un fundamento trascendental -autor, texto, historia- que pueda regular los límites de la interpretación, sí existe una comunidad en la cual el crítico pone a funcionar sus capacidades retóricas y poéticas para elaborar interpretaciones persuasivas. La fortaleza de la argumentación regula así los límites de la interpretación. En este marco, el autor es un argumento construido por el lector que se configura como parte del engranaje que constituye la obra y que resulta en el marco de un paradigma y de una biblioteca colectiva en los que habita.

No hay, desde esta perspectiva, un autor por fuera de la obra literaria, es decir por fuera del acontecimiento de la lectura. El autor es un elemento más de la obra, elaborado por el lector, quien lo concibe en el mismo momento en que experimenta su propia subjetivación durante el leer, determinado él también por el paradigma y la biblioteca colectiva a los que pertenece, así como por el libro interior que no cesa de no escribir. El autor es un argumento en el marco de un ejercicio crítico en el que el lector se inscribe, produciendo un texto poética y retóricamente configurado, anhelo de un librointerior siempre por venir $\mathbf{C}$ 


\section{Referencias}

Barthes, R. (2002 [1968]). La mort de l'auteur. En CEuvres complètes (Tomo III). Paris: Seuil.

Bayard. P. (2002). Enquête sur Hamlet. Paris: Minuit.

Bayard. P. (2007). Comment parler des livres que l'on n'a pas lus ? Paris: Minuit.

Bayard. P. (2009). Le plagiat par anticipation. Paris: Minuit.

Bayard. P. (2010). Et si les ceuvres changeaient d'auteur? Paris: Minuit.

Bayard, P. (2017). L'énigme Tolstoïevski. Paris: Minuit.

Bellemin-Noël, J. (1985). L'auteur encombrant : Stendhal/Ambran. Lille: Presses Universitaires du Septentrion.

Bloom, H. (1997). The Anxiety of Influence. Oxford: Oxford University Press.

Booth, W. C. (1983). The Retoric of Fiction (2a ed). Chicago-London: Chicago University Press.

Borges, J. L. (1998). Ficciones. Madrid: Alianza.

Braudel, F. (1993). La Méditerranée et le monde méditerranéen à l'époque de Philippe II, Tome 1. La Part du milieu. Paris: Poche.

Burke, J. (1989). The Death and Return of the Author. Edinburgh: University of Edinburgh.

Couturier, M. (1995). La figure de l'auteur. Paris: Seuil.

Fish, S. (1980). Is There a Text in This Class? The Authority of Interpretive Communities. Cambridge, MA: Harvard University Press.

Foucault, M. (1994 [1969]). Qu'est-ce qu'un auteur ? En Dits et écrits (Tomo I). Paris: Gallimard.

Garayalde, N. (2014). Las conveniencias de la no-lectura. Córdoba: Alción.

Garayalde, N. (2018). La lectura del tiempo en la obra de Pierre Bayard. Çedille, revista de estudios franceses, 14, 221-243.

Genette, G. (1982). Palimpsestes. La littérature au second degré. Paris: Seuil. Holland, N. (1973). Poems in persons. New York: The Northon Library.

Holland, N. (1975). Hamlet -my Greatest Creation. Journal of the American Academy of Psychoanalysis, 3(4), 419-427.

Holland, N. (1985). The I. New Haven and London: Yale University Press. Iser, W. (1987). El acto de leer. Madrid: Taurus. 
Jauss, H. R. (1987). El lector como instancia de una nueva historia de la literatura. En J. A. Mayoral (Comp.), Estética de la recepción (pp. 59. 85). Madrid: Arco Libros.

Jones, E. (1957). The Life and Work of Sigmund Freud (Vol. 3). New York: Basic Books.

Jouve, V. (2008). Auteur et littérarité. Cycnos, 14(2). Recuperado de https:// bit.ly/2Lgczro

Kuhn, T. (1971). La estructura de las revoluciones científicas. México: F. C. E.

Lacan, J. (2006). El seminario. Libro XX. Aún. Buenos Aires: Paidós.

Lawrence, D. H. (2012 [1928]). El amante de lady Chatterley. Madrid: Alianza.

Lawrence, T. E. (1989 [1926]). Los siete pilares de la sabiduría: Madrid: Jucar.

Lecercle, J.-J. (2008). Lire Couturier. Cycnos, 14(2). Recuperado de https:// bit.ly/2JPPuGk

Looney, T. (2010 [1920]). "Shakespeare" identified in Edward De Vere, the seventeenth Earl of Oxford. Memphis, Tenn: General Books LLC.

Nehamas, A. (1987). Writter, Text, Work, Author. En A. Cascardi (Ed.), Literature and the Question of Philosophy (pp. 267-291). Baltimore: John Hopkins University Press.

Ocampo, V. (2013 [1963]). 338171 T. E. Lawrence de Arabia. Buenos Aires: Letemendia.

Rabau, S. (2011). Lire contre l'auteur. Paris: PUV.

Rolph, C. H. (2005 [1961]). Lady Chatterley's Trial. Regina v. Penguin Books Limited: the transcript of the trial. London: Penguin Books.

Stewart, D. (1977). T. E. Lawrence. London: Granada Publishing Limited.

Topuzian, M. (2014). Muerte y resurrección del autor (1963-2005). Santa Fe: UNL.

Vernet, M. (2011). L'auteur en soupçon: déjouer la fiction d'autorité. En S. Rabau (Ed.), Lire contre l'auteur (pp. 99-115). Paris: PUV. 